\title{
Changes in epidermal radiosensitivity with time associated with increased colony numbers
}

\author{
${ }^{1} \mathrm{G} J \mathrm{M} J$ VAN DEN AARDWEG, PhD, ${ }^{2} \mathrm{G}$ M MORRIS, PhD, ${ }^{2} \mathrm{~A}$ BYWATERS, ${ }^{1} \mathrm{E} \mathrm{J}$ BAKKER and \\ ${ }^{3} \mathrm{~W} J \mathrm{MOOI}, \mathrm{MD}$ \\ ${ }^{1}$ Department of Radiation Oncology, Subdivision of Clinical Radiobiology, University Hospital Rotterdam- \\ Daniel den Hoed Cancer Center/Dijkzigt Hospital, Josephine Nefkens Institute, PO Box 1738, 3000 DR \\ Rotterdam, The Netherlands, ${ }^{2}$ Normal Tissue Radiobiology Research Group, Research Institute (University \\ of Oxford), Churchill Hospital, Oxford OX3 7LJ, UK and ${ }^{3}$ Department of Pathology, The Netherlands Cancer \\ Institute, Plesmanlaan 121, 1066 CX Amsterdam, The Netherlands
}

\begin{abstract}
Epidermal clonogenic cell survival and colony formation following irradiation were investigated and related to radiosensitivity. A rapid in vivo/in vitro assay was developed for the quantification of colonies arising from surviving clonogenic cells in pig epidermis after irradiation. Bromodeoxyuridine (BrdU)-labelled cells in full thickness epidermal sheets were visualized using standard immunohistochemistry. In unirradiated skin, $\approx 900$ BrdU-positive cells $\mathrm{mm}^{-2}$ were counted. In a time sequence experiment, BrdU-positive cell numbers increased from an average of 900 cells $\mathrm{mm}^{-2}$ to approximately 1400 cells $\mathrm{mm}^{-2}$ after BrdU-labelling for $2-24 \mathrm{~h}$. In irradiated skin, colonies containing $\geqslant 16$ BrdU-positive cells were seen for the first time at days 14/15 after irradiation. The number of these colonies per $\mathrm{cm}^{2}$ as a function of skin surface dose yielded a cell survival curve with a $D_{0}$-value $( \pm \mathrm{SE})$ of $3.9 \pm 0.6$ Gy. This relatively high $D_{0}$-value is possibly due to a rapid fall off in depth dose distribution for the iridium-192 source and consequently a substantial contribution of hair follicular epithelium to colony formation. At 14/15 days after irradiation, the $\mathrm{ED}_{50}$ level of $33.6 \mathrm{~Gy}$ for the in vivo response of moist desquamation corresponded with 2.7 colonies $\mathrm{cm}^{-2}$. Surprisingly, the number of colonies increased with time after irradiation with an estimated doubling time of $\approx 4$ days, while the $D_{0}$-value remained virtually unchanged. This increase in colony numbers could be due to migration of clonogenic cells, to the recruitment of dormant clonogenic cell survivors by elevated levels of cytokines, or to both. Although frequent biopsying caused increased cytokine levels, which had a systemic effect on unirradiated skin, it had no influence on colony formation in irradiated skin. Smaller colonies, containing 4-8 cells or 9-15 cells, were abundant, particularly after higher doses, which resulted in higher $D_{0}$-values. The majority of these small colonies were abortive and did not progress to larger colonies. There was no statistical evidence for significant variations in the interanimal responses.
\end{abstract}

Acute epidermal injuries to the skin following radiotherapy are often assessed using the relatively crude macroscopic reactions of erythema and moist desquamation. These reactions can be observed in pig skin at 4-6 weeks after irradiation. It is assumed that the severity and incidence of moist desquamation is inversely related to the number of clonogenic cell survivors. However, the dose-effect relationships for erythema and moist desquamation may be influenced by environmental factors, such as infections, partially aggravating the radiation effects. Moreover, there is little knowledge about the characteristics of the colonies arising from the surviving clonogenic cells after irradiation. For this purpose, a quantitative

Received 4 February 2000 and in revised form 2 October 2000, accepted 20 October 2000. assay was developed to determine colony formation in pig epidermis [1]. For our study, we adopted this assay and modified it using in vitro labelling with bromodeoxyuridine (BrdU) followed by standard immunohistochemistry [2]. In the past, various studies have been carried out to determine radiation damage to the epidermis using the number of colonies arising from surviving clonogenic cells as a parameter for radiosensitivity [3-9]. Different types of assay have been used, such as a macroscopic in vivo colony assay for rodent skin $[4,5,8]$, autoradiographs of whole epidermal sheets for the detection of proliferating cells in mouse skin [3], crosssections of pig skin for light microscopy [10] and counting mitotic figures in whole epidermal sheets from pig skin biopsies [1]. However, all these assays had limitations; in the macroscopic colony 
assay [8], the skin colonies were only visible in one particular mouse strain and smaller colonies could easily be missed, while the use of autoradiographs and cross-sections is laborious and time consuming. The assay introduced by Chen et al [1] required repeated injections of vincristine followed by a vigorous process of epidermal and dermal separation involving $5 \mathrm{~N} \mathrm{HCl}$ after biopsying.

The objective of this paper is to describe a rapid, quantitative in vivo/in vitro assay to detect colonies in pig epidermis using standard immunohistochemistry. Data on colony formation over a period of 10-26 days after irradiation are presented. For this study, skin fields were irradiated with an iridium-192 source, since in vivo data for this type of source were already available in our laboratory [11]. Factors that could possibly influence the number of proliferating cells, such as basal cell density and epidermal thickness, were investigated in relation to field position on the flank.

\section{Materials and methods}

\section{Irradiation}

Young female pigs of the Yorkshire strain, weighing $\approx 25 \mathrm{~kg}$, were purchased from a commercial supplier. A total of 15 fields, $3 \mathrm{~cm} \times 3 \mathrm{~cm}$, were tattooed on each flank. Prior to irradiation the animals were sedated with ketamine and stresnil, while during irradiation an anaesthetic gas mixture of $\approx 70 \%$ oxygen, $\approx 30 \%$ nitrous oxide and $1-2 \%$ halothane was administered [12, 13]. The skin fields were irradiated with an iridium192 stepping source from a high dose rate microSelectron (Nucletron, Veenendaal, The Netherlands). The microSelectron was connected with an array of four parallel, equidistant catheters in a $5 \mathrm{~cm} \times 5 \mathrm{~cm}$ flexible silicon template taped to the skin. The four catheters, $1 \mathrm{~cm}$ apart, covered the $3 \mathrm{~cm} \times 3 \mathrm{~cm}$ field. The distance between the axis of the catheters and the skin surface was $5 \mathrm{~mm}$. The stepping source was programmed with the Nucletron Planning System (NPS), such that each catheter contained seven dwell positions at a distance of $5 \mathrm{~mm}$, i.e. a total of 28 positions over the entire field. The dwell times for each source position were optimized using the NPS such that the dose variations over a distance of $5 \mathrm{~mm}$ in a plane field were minimized, with the $100 \%$ isodose at the skin surface. The 95\% isodose was around the basal layer, while the $80 \%$ isodose covered the dermisfat layer (for further details see Hamm et al [11]). The skin fields were irradiated with single doses of 20 Gy, 24 Gy, 27 Gy, 30 Gy, 32 Gy, 36 Gy and
$40 \mathrm{~Gy}$ at the skin surface, with dose rates ranging from $0.9-1.7 \mathrm{~Gy} \mathrm{~min}^{-1}$.

\section{Biopsies}

In the first experiment, involving three pigs, biopsies were taken from irradiated fields over a period of 10-26 days after irradiation. A total of 57 fields was available for analysis. After biopsying, the animals were allowed to recover. At day 26, after the final biopsy, the animals were sacrificed. In an additional experiment, biopsies were taken only at days $24 / 25$ after irradiation from two pigs, which resulted in 22 fields available for analysis. The skin biopsies, $4 \mathrm{~mm}$ in diameter, were taken under full gas anaesthesia (oxygen, nitrous oxide, 4-5\% halothane). Biopsies from irradiated skin fields and unirradiated areas were taken between 9.00am and 11.00am to avoid any possible diurnal variation in histological and cell kinetic parameters. A total of 16 biopsies were collected from each irradiated field, avoiding the edges of the field.

In these irradiated animals, 16 biopsies were also taken from unirradiated dorsal as well as from lateral and ventral parts of the flank at various times before and after irradiation. In 11 control pigs of the same strain, $\approx 7$ months of age, 16 biopsies were taken from each of unirradiated dorsal, lateral and ventral flank areas.

\section{Immunohistochemistry}

The immunohistochemical procedure has been described in detail previously [2]. Briefly, biopsies were incubated in $0.5 \%$ dispase (Boehringer, Mannheim, Germany) to separate epidermis and dermis. This mild protease treatment allowed gentle separation of the epidermis and dermis with forceps. The epidermis remained intact as a full epidermal sheet [14, 15]. Each epidermal sheet was incubated separately in $1 \mathrm{ml} \mathrm{DMem} / \mathrm{HamF} 12$ medium with $300 \mu \mathrm{M}$ BrdU for $24 \mathrm{~h}$ at $37{ }^{\circ} \mathrm{C}$. The specimens were further processed with $70 \%$ ethanol, $1 \mathrm{~N} \mathrm{HCl}$ and a borax solution before incubation overnight with a monoclonal antibody specifically recognizing BrdU (Mab-BrdU). This was followed by a rabbit anti-mouse conjugated peroxidase (Ram-Po). The epidermal sheets were stained with 3,3'-diaminobenzidine tetrahydrochloride dihydrate (DAB). Between each step, the epidermal sheets were washed with saline and $1 \%$ bovine serum albumin. Fixation of the epidermal sheets was by graded ethanol incubations, followed by xylol/100\% ethanol and xylol only. The epidermal sheets were covered with a standard glass coverslip and examined microscopically. Omission of Mab-BrdU, Ram-Po or $\mathrm{DAB}$ constituted the negative controls. 


\section{Analysis}

The epidermal sheets, with an average size of 3-6 $\mathrm{mm}^{2}$, were examined microscopically at a magnification factor of 200. Tightly packed, distinct cell clusters in the basal layer, containing at least 16 brown BrdU-positive nuclei, indicative of DNA incorporation, were counted. Cell clusters seen on the shaft of hair follicles were not included in the analysis. Using a standard ocular grid, the total area screened in each biopsy was converted to metrical units using the Vernier scales. The number of colonies counted in each biopsy was expressed per $\mathrm{cm}^{2}$ and the results of 16 biopsies obtained from one irradiated field were averaged. 2-6 fields were used per dose point and the mean number of colonies per $\mathrm{cm}^{2}$ in these fields was calculated. Biopsies where colonies had merged to form very large colonies, indicating the epithelium returning to a normal situation, were excluded from analysis. This merging of colonies was mainly seen at days 24-26 after irradiation, but only after lower doses. Expressing the mean number of colonies per $\mathrm{cm}^{2}$ as a function of dose provided cell survival curves, which were analysed using linear regression analysis.

Interanimal variation was analysed using ANOVA (MS Excel 97), with a $p$-value $<0.05$ (two-sided) regarded as significant.

More than 1000 BrdU-labelled cells were counted in biopsies from unirradiated skin in an area covering at least four ocular grids. The number of BrdU-positive cells was expressed per $\mathrm{mm}^{2}$.

\section{Basal cell density}

Before sacrifice of irradiated animals, an additional two biopsies were taken from dorsal, lateral and ventral areas of the flank for basal cell density (BCD) counts. At four locations in each of these biopsies, at least $100 \mu \mathrm{m}$ apart, $10 \mu \mathrm{m}$ paraffin sections were cut, stained with hematoxylin/eosin and prepared for BCD counting. Cells at the basal membrane were counted along the undulations of the rete pegs and expressed per mm length [16].

\section{Skin thickness}

In a separate experiment, biopsies from Yorkshire pigs, $\approx 3$ months of age, were taken for measurements of epidermal thickness. A total of three biopsies, $6 \mathrm{~mm}$ in diameter, from each of dorsal, lateral and ventral areas, were used. Sections of $5 \mu \mathrm{m}$ were stained with hematoxylin/ eosin. A total of 10 sections per biopsy were analysed. Light microscopy images at a magnification factor of 10 were recorded with a cooled charged coupled device (CCD) camera and displayed on a monitor. A given distance on the monitor was expressed in number of pixels. At this magnification factor, a length of $1 \mathrm{~mm}$ was equivalent to 154 pixels. The minimum and maximum distance of skin surface to basal membrane was measured. Results of the three biopsies per flank site were averaged.

\section{Approval}

This study was approved by the animal ethical committee of the Medical Faculty, Erasmus University Rotterdam (protocol number 605.93.03). All procedures with animals were carried out according to the guidelines set by this committee.

\section{Results}

After incubation with the enzyme dispase, a full thickness epidermal sheet was always obtained with normal morphology and an intact basal layer (Figure 1A). All other keratinocyte layers, including the cornified layer, were also intact (Figure 1A).

\section{Unirradiated epidermis}

Initially, a labelling period of $24 \mathrm{~h}$ was used to ensure that $\mathrm{BrdU}$ penetrated the epidermis sufficiently, not only because full thickness epidermal sheets were used, but also because the cell cycle time of basal cells was estimated to be 16-22 $\mathrm{h}$ following irradiation [16]. In unirradiated skin, BrdU-positive cells were easily distinguished from their non-labelled neighbours and were seen either as solitary cells (Figure 1B) or as pairs (Figure 1C). In 11 control animals, on average 882 (SE 92; range 467-1584) BrdU-labelled cells per $\mathrm{mm}^{2}$ of epidermis were counted (Figure 2). No significant difference in the number of BrdUpositive cells was seen with flank position. In the young, irradiated pigs (pigs A and B), biopsies from unirradiated skin contained an average of $916 \pm 149\left(\right.$ mean \pm SE) BrdU-labelled cells $\mathrm{mm}^{-2}$ prior to biopsying of the irradiated skin fields. Again, no significant differences were observed between different flank sites. However, once frequent biopsying of irradiated skin fields began from days 10-26 after irradiation, the number of BrdU-positive cells in the unirradiated skin increased significantly by a factor of 2.5-3; for pig A a $p$-value of $<0.007$ was calculated; for pig B this was $<0.002$ (Figure 2). In a second experiment (pigs $\mathrm{C}$ and $\mathrm{D}$ ), where all skin fields were biopsied simultaneously at days 24/25 after irradiation, the number of BrdU-labelled cells was higher, but remained constant at around 1600 cells $\mathrm{mm}^{-2}$ throughout the treatment, with 

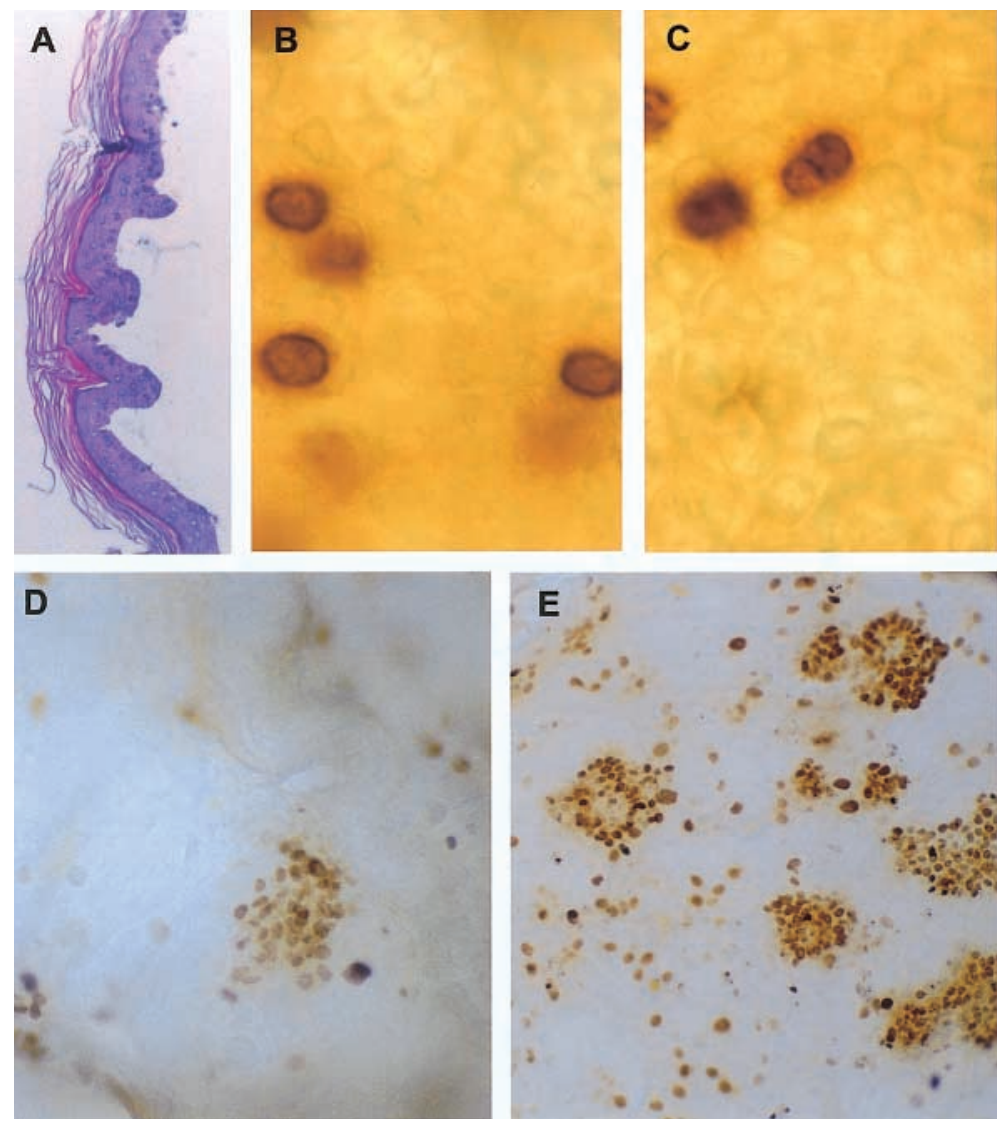

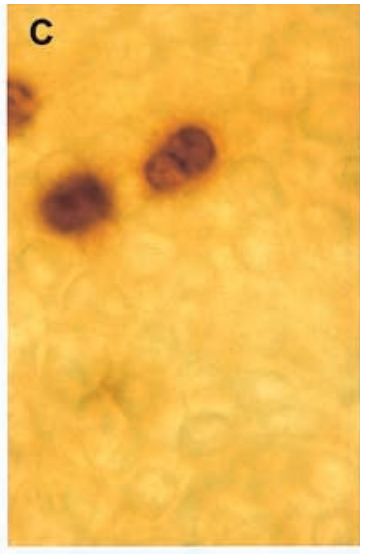

Figure 1. (A) Histological crosssection of pig epidermis after enzymatic separation with dispase. Notice that all epidermal cell layers are present and that the undulations of the basal membrane are intact. H\&E staining, magnification $\times 100$. (B,C) Bromodeoxyuridine (BrdU)-positive cells in the dorsal area of unirradiated pig epidermis, either as a solitary cell (B) or as pairs (C). Magnification $\times 1000$. (D,E) Colonies containing $>16$ tightly packed, BrdU-positive cells at 14 days (D) and 25 days (E) after a single dose of $27 \mathrm{~Gy}$. Magnification $\times 200$. no significant difference with regard to flank position (Figure 2).

In a separate study involving two pigs (pigs E and $F$ ) at $\approx 3$ months of age, for each time point ranging from $2-24 \mathrm{~h}$ a total of 16 dorsal,

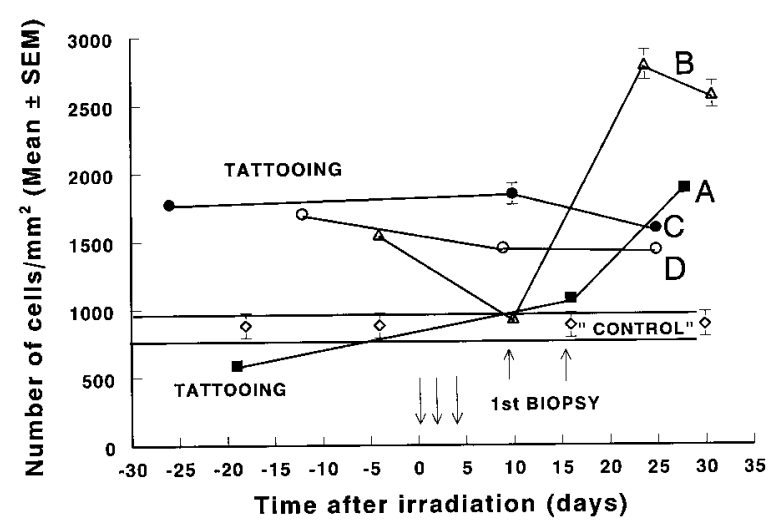

Figure 2. Changes in number of bromodeoxyuridine (BrdU)-positive cells in the unirradiated skin of young pigs, $\approx 3$ months of age, prior to and after irradiation. For pigs $\mathrm{A}$ and $\mathrm{B}$, the irradiated skin fields were biopsied over a period of 10-26 days after irradiation. For pigs $\mathrm{C}$ and $\mathrm{D}$, all irradiated skin fields were biopsied at the same time at 24/25 days after irradiation. The mean number of BrdU-labelled cells in 11 control animals, $\approx 7$ months of age, is indicated for comparison. (See discussion for explanation of the significantly higher number of BrdU-positive cells 4 days prior to irradiation in pig B.) Arrows between days $0-5$ indicate irradiation sessions.
16 lateral and 16 ventral biopsies were labelled in vitro with BrdU (Figure 3). With $2-4 \mathrm{~h}$ of BrdU labelling, a total of around 800-1000 positive cells $\mathrm{mm}^{-2}$ was counted. This number increased with longer BrdU labelling times. This increase in BrdU-positive cells accounted for an increase in paired cells from an initial level of $12 \%$ to more than $50 \%$ of the total number after $24 \mathrm{~h}$ of BrdU labelling (Figure 3). Surprisingly, the number of solitary cells hardly changed over this time period (data not shown).

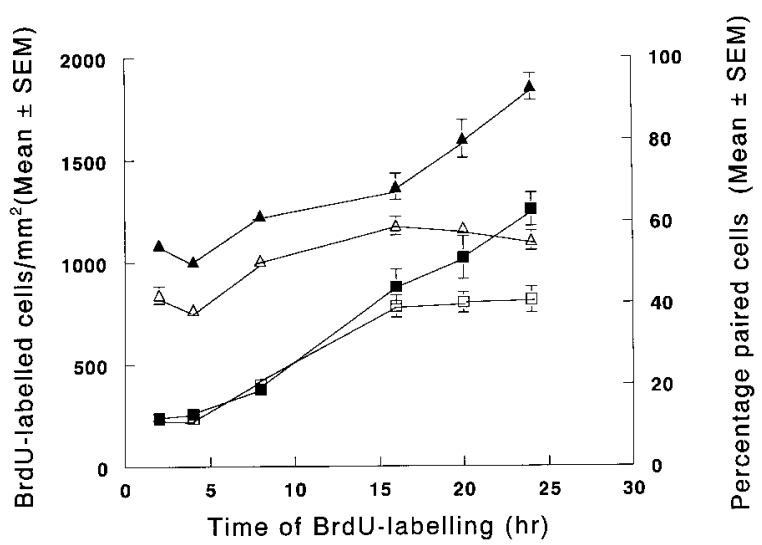

Figure 3. Changes in number of bromodeoxyuridine (BrdU)-positive cells $(\triangle, \mathbf{\Lambda})$ and the percentage of paired cells $(\square, \boldsymbol{\square})$ in unirradiated pig epidermis with increasing time after BrdU labelling. The results for two young pigs, pig E (open symbols) and pig F (solid symbols) are presented. 
Factors that could possibly influence the number of proliferating cells per unit area, such as BCD and epidermal thickness, were investigated. The overall $\mathrm{BCD}$ in young Yorkshire pigs was on average 157 cells $\mathrm{mm}^{-1}$, and did not differ significantly between biopsy sites (Table 1). The average diameter of basal cells was $7 \mu \mathrm{m}$ and that of the first suprabasal cells was $10 \mu \mathrm{m}$. Epidermal thickness, as measured in histological skin sections, was also constant between flank sites, with an average of $63 \mu \mathrm{m}$ and $117 \mu \mathrm{m}$ for minimal and maximal epidermal thickness, respectively (Table 1).

\section{Irradiated epidermis}

In irradiated skin fields, colonies containing $\geqslant 16$ BrdU-positive cells, i.e. cells that had undergone at least four cell divisions, were easily recognized (Figures 1D,E). This level of $\geqslant 16$ cells per colony was chosen to exclude very small colonies as these smaller colonies probably do not contribute significantly to re-epithelialization [10]. At 10 days after a single dose of $20 \mathrm{~Gy}$, no BrdU-labelled cell clusters containing $\geqslant 16$ cells could be observed. Occasionally, solitary BrdU-positive cells were seen. At days 14/15 after irradiation, the first colonies containing at least 16 cells were seen. In nearly all colonies the BrdUlabelled cells were tightly packed together as a cluster (Figures 1D,E). Even if the clustering of BrdU-labelled cells was less tight, they could still be recognized as belonging to one colony, since the surrounding area showed only a scattering of positive, solitary cells. The number of colonies per $\mathrm{cm}^{2}$ at $14 / 15$ days after irradiation, expressed as a function of skin surface dose, is presented in Figure 4. The slope of this cell survival curve, as indicated by the $D_{0}$-value $( \pm \mathrm{SEM})$ is $3.9 \pm 0.6 \mathrm{~Gy}$ (Table 2).

Three different levels for the incidence of moist desquamation, $\mathrm{ED}_{20}, \mathrm{ED}_{50}$ and $\mathrm{ED}_{80}$, as obtained from the in vivo study carried out with the same strain of pig and the same irradiation and anaesthetic procedures [11], are included for comparison. The $\mathrm{ED}_{50}$ value $(95 \%$ confidence interval) for moist desquamation at the skin surface of 33.6 (32.0-35.1) Gy corresponded with $2.7(4.0-1.8)$ colonies $\mathrm{cm}^{-2}$ (Table 2).

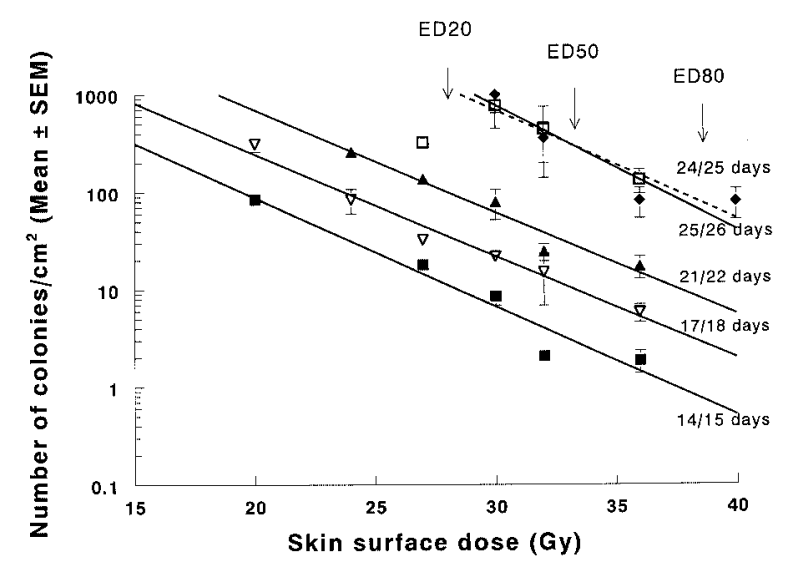

Figure 4. Cell survival curves for colonies in pig epidermis containing $\geqslant 16$ bromodeoxyuridine-positive cells at different times after various levels of irradiation. - Frequent biopsying of different skin fields in the same animals over a short period of time after irradiation; ----, biopsying of all skin fields simultaneously after irradiation. Three different levels, $\mathrm{ED}_{20}$, $\mathrm{ED}_{50}$ and $\mathrm{ED}_{80}$, for the incidence of moist desquamation as obtained from an in vivo study are indicated for comparison.

In the same animals, other skin fields were biopsied at later stages after irradiation and the cell survival curves for these time periods are also presented in Figure 4. The $D_{0}$-values for these curves were all approximately $3.5-4.0 \mathrm{~Gy}$ (Table 2). Surprisingly, the extrapolation number increased substantially with time after irradiation (Table 2). This increase in colony number was also reflected by a 100 -fold increase in the number of colonies per $\mathrm{cm}^{2}$ corresponding with the in vivo $\mathrm{ED}_{50}$ value for moist desquamation between days 14/15 and days 25/26 after irradiation (Figures 1D,E). A doubling time of $\approx 4$ days for the number of colonies was calculated from these cell survival curves. The responses of the three pigs involved in this experiment were not significantly different for any of the four time points of biopsying; 14/15 days $(p>0.16), 17 / 18$ days $(p>0.94), 21 / 22$ days $(p>0.21)$ and $25 / 26$ days $(p>0.09)$.

In an additional experiment, all irradiated skin fields were biopsied at one time point, at 24/25 days after irradiation. The cell survival curve was very similar to that obtained for days 25/26, where frequent biopsying of different fields in the

Table 1. Basal cell density (BCD) and epidermal thickness in Yorkshire pigs in relation to flank position

\begin{tabular}{llllll}
\hline Flank position & \multicolumn{2}{l}{ BCD $\left(\right.$ cells mm $\left.\mathrm{mm}^{-1}\right)($ mean \pm SEM $)$} & & \multicolumn{2}{l}{ Epidermal thickness $(\mu \mathrm{m})(\mathrm{mean} \pm \mathrm{SEM})$} \\
\cline { 2 - 3 } \cline { 5 - 6 } & Pig 1 & & Pig 2 & Minimum & Maximum \\
\hline Dorsal & $154 \pm 8.4$ & $154 \pm 9.2$ & & $64.4 \pm 2.0$ & $111 \pm 3.6$ \\
Lateral & $163 \pm 9.6$ & $161 \pm 3.9$ & & $62.7 \pm 1.6$ & $121 \pm 3.5$ \\
Ventral & $158 \pm 10.1$ & $157 \pm 7.6$ & & $62.9 \pm 1.4$ & $119 \pm 3.2$ \\
Overall & $158 \pm 2.6$ & $157 \pm 2.0$ & & $63.3 \pm 0.5$ & $117 \pm 3.1$ \\
\hline
\end{tabular}


Table 2. Parameters for cell survival curves for colonies containing $\geqslant 16$ bromodeoxyuridine-positive cells at different times after irradiation

\begin{tabular}{llcrrr}
\hline $\begin{array}{l}\text { Days after } \\
\text { irradiation }\end{array}$ & $\begin{array}{l}D_{0} \text {-values (Gy) } \\
(\text { mean } \pm \text { SEM) }\end{array}$ & $\begin{array}{l}\text { Extrapolation number } \times 10^{-3} \\
\text { (mean } \pm \text { SEM) }\end{array}$ & \multicolumn{2}{c}{ Colonies per $\mathrm{cm}^{2}$} \\
\cline { 4 - 6 } ED $_{20}$ & ED $_{50}$ & ED $_{80}$ \\
\hline $14 / 15$ & $3.9 \pm 0.6$ & $15.1 \pm 1.7$ & 10 & 2.7 & 0.7 \\
$17 / 18$ & $4.1 \pm 0.3$ & $33.7 \pm 1.8$ & 34 & 9.2 & 2.6 \\
$21 / 22$ & $3.5 \pm 0.5$ & $341 \pm 33$ & 113 & 25 & 5.8 \\
$25 / 26$ & $3.5 \pm 0.5$ & $3556 \pm 314$ & 1139 & 252 & 58 \\
$24 / 25$ & $3.9 \pm 1.1$ & $1507 \pm 278$ & 1076 & 277 & 73 \\
\hline
\end{tabular}

same animals had been carried out over a period of 10-26 days after irradiation (Figure 4). The $D_{0}$-values of these curves, as well as the number of colonies per $\mathrm{cm}^{2}$ corresponding with the three levels for moist desquamation, were very similar (Table 2). For the two animals involved in this experiment, the interanimal variation did not reach levels of significance $(p>0.059)$.

Close examination of the biopsies showed that, apart from large colonies containing $\geqslant 16 \mathrm{BrdU}$ positive cells, smaller colonies were also present. All colonies were arbitrarily divided according to size as containing either 4-8, 9-15, 16-31 and $\geqslant 32$ BrdU-positive cells. At day 10 after $20 \mathrm{~Gy}$, only colonies with 4-8 cells were seen, with an average of $23.5 \pm 0.2$ colonies $\mathrm{cm}^{-2}$ (mean $\pm \mathrm{SE}$ ). At later stages after irradiation, all four colony types were observed. The number of colonies per $\mathrm{cm}^{2}$, expressed as a function of skin surface dose, is presented in Figure 5 for different sized colonies and at various times after irradiation. The smaller colonies, particularly the very small ones of 4-8 BrdU-positive cells, were abundant up to 22 days after irradiation. However, at 25/26 days after irradiation the very small colonies (4-8 cells) were absent (Figure 5d). Large colonies with $\geqslant 32$ BrdU-labelled cells were extremely rare at 14/15 days after irradiation; in one field after 27 Gy there was one such colony, while after 30 Gy three colonies with $\geqslant 32$ cells were seen (Figure 5a). For the different time periods after irradiation the number of colonies corresponding with the $\mathrm{ED}_{50}$ level for moist desquamation are presented for the four colony types (Table 3). As time progressed, the large colonies became more abundant.

Surprisingly, the $D_{0}$-value varied with colony size. For the larger colonies containing $\geqslant 16$ BrdU-positive cells, there was a trend towards smaller $D_{0}$-values of $3.0-4.0 \mathrm{~Gy}$ (Table 4). The $D_{0}$-values for the smaller colonies (4-8 cells and 9-15 cells) were much higher and ranged from 7.1-9.8 Gy. These changes in $D_{0}$-values with colony size were independent of time after irradiation. Apparently, the higher doses resulted in relatively large numbers of small colonies.

\section{Discussion}

In this paper, results are presented of a quantitative assay on the radiosensitivity of pig epidermis using colony numbers arising from clonogenic cell survivors. Enzymatic separation of pig epidermis and dermis produced morphologically intact epidermal sheets with a normal appearance of the various epidermal layers. Whole epidermal sheets were incubated with BrdU, followed by immunohistochemistry. A standard immunohistochemical procedure was adapted to meet the requirements for these specimens. BrdU-positive cells, indicative of DNA incorporation, could be visualized with this technique in both irradiated and unirradiated epidermal sheets. Colonies, i.e. tightly packed clusters of brown nuclei, could be recognized.

\section{Unirradiated epidermis}

The interanimal variation for BrdU-positive cells was approximately 3.4-fold in the older "control" pigs. In this first attempt, various steps could contribute to this variability, such as enzymatic separation, BrdU labelling and/or immunohistochemistry, all influencing the total number of BrdU-positive cells. In the first irradiation experiments, biopsies from unirradiated skin also indicated considerable interanimal variations (pigs $\mathrm{A}$ and $\mathrm{B} v s$ pigs $\mathrm{C}$ and $\mathrm{D}$ ). For this purpose, the effects of variable BrdU labelling times were investigated (Figure 3). For up to $16 \mathrm{~h}$, a similar increment in the number of BrdU-positive cells was observed for two animals (pigs $\mathrm{E}$ and F). Only with labelling times between 16-24 h did a deviation occur. Apparently, culture conditions became less favourable during longer labelling periods, which might explain some of the interanimal variations observed in the "control" pigs.

The overall increase in BrdU-positive cells with longer labelling periods is only reflected in increased numbers of paired cells, while the number of solitary cells remained more or less constant. The initial $12 \%$ of paired cells mainly reflected BrdU-positive cells seen as pairs by coincidence. The steady increase in paired cells 


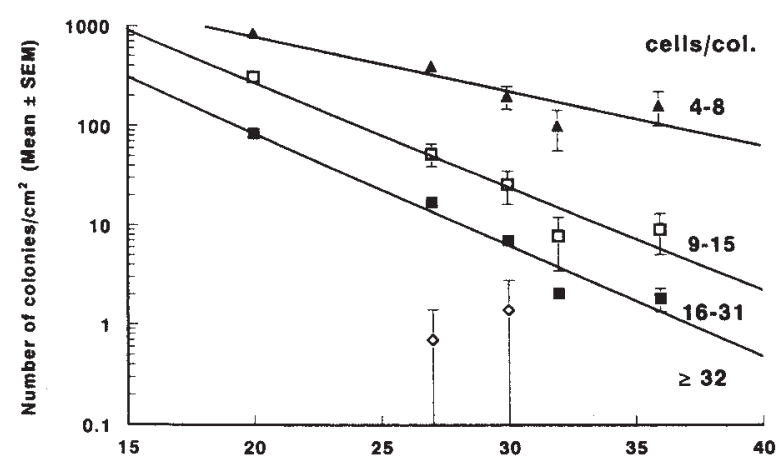

(a)

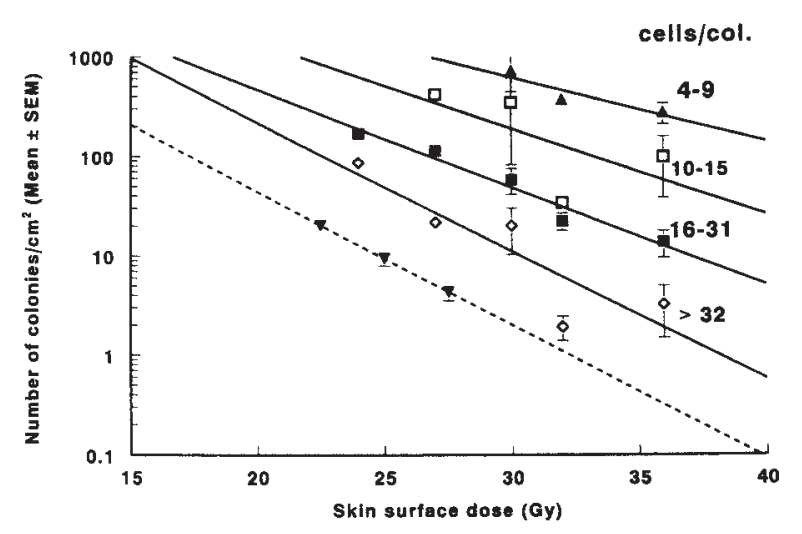

(c)

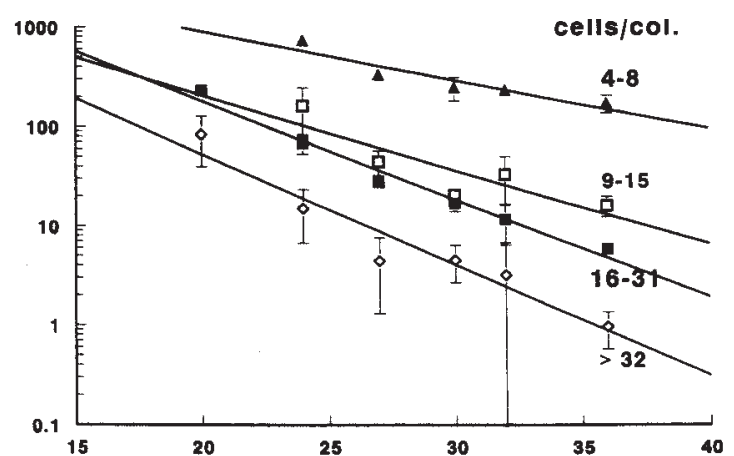

(b)

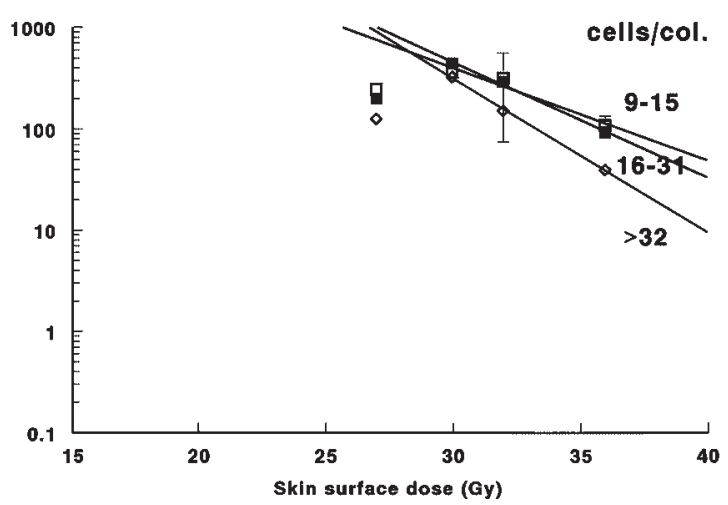

(d)

Figure 5. Cell survival curves for colonies in pig epidermis containing different numbers of bromodeoxyuridine (BrdU)-positive cells. The four categories of colony size are indicated by the number of BrdU-positive cells per colony. Skin biopsies were taken at (a) 14/15 days, (b) 17/18 days, (c) 21/22 days and (d) 25/26 days after irradiation. Data for 27 Gy at 25/26 days after irradiation (d) were not included in the analysis. Data obtained by Chen et al [1], using a comparable clonogenic assay, are indicated in (c) for comparison ( $\boldsymbol{\nabla}---\nabla)$.

with longer BrdU labelling periods and the fact that the number of solitary cells remained constant could indicate that cell separation ceased immediately after mitosis.

Variations in BCD and epidermal thickness were considered as potential factors influencing the total number of BrdU-positive cells counted. In this study, the interanimal and intraanimal variations for $\mathrm{BCD}$ were not significant (Table 1). A much higher BCD of $198-208$ cells $\mathrm{mm}^{-1}$ was published for the Yorkshire pig [17]. However, these results are not directly comparable because basal cells were counted along a stretch of $1 \mathrm{~cm}$, ignoring the undulations of the basal membrane and resulting in an overestimate of the $\mathrm{BCD}$ per unit basal membrane. For the genetically related strain of pig, Large White, a very similar BCD of 143 cells mm ${ }^{-1}$ was reported where the basal cells were counted along the undulations of the basal membrane $[18,19]$. With a mean diameter of $7 \mu \mathrm{m}$ and $10 \mu \mathrm{m}$ for basal cells and first suprabasal cells, respectively, a total of $30.4 \times 10^{3}$ cells $\mathrm{mm}^{-2}$ was calculated for the two layers together. Since BrdU-positive cells in the basal and suprabasal layers were indistinguishable, a total of 1000 BrdU-positive cells $\mathrm{mm}^{-2}$ would correlate with a labelling index (LI) of $3.3 \%$, while 1800 cells $\mathrm{mm}^{-2}$ would be equivalent

Table 3. Number of colonies per $\mathrm{cm}^{2}$ corresponding with the in vivo $\mathrm{ED}_{50}$ level for moist desquamation in relation to colony size and time after irradiation

\begin{tabular}{|c|c|c|c|c|}
\hline \multirow[t]{2}{*}{ Days after irradiation } & \multicolumn{4}{|c|}{ Colony size } \\
\hline & 4-8 cells & $9-15$ cells & 16-31 cells & $\geqslant 32$ cells \\
\hline $14 / 15$ & 146 & 10.5 & 2.5 & er \\
\hline $17 / 18$ & 216 & 19 & 8.0 & 1.1 \\
\hline $21 / 22$ & 380 & 96 & 21 & 3.8 \\
\hline $25 / 26$ & er & 191 & 180 & 66 \\
\hline $24 / 25$ & 76 & 160 & 160 & 116 \\
\hline
\end{tabular}

er, extremely rare or non-existent. 
Table 4. $D_{0}$-values $( \pm \mathrm{SE})$ for colonies of different size and at different times after irradiation

\begin{tabular}{|c|c|c|c|c|}
\hline \multirow[t]{2}{*}{ Days after irradiation } & \multicolumn{4}{|c|}{ Colony size } \\
\hline & $4-8$ cells & $9-15$ cells & $16-31$ cells & $\geqslant 32$ cells \\
\hline $14 / 15$ & $8.0 \pm 2.3$ & $4.2 \pm 0.7$ & $3.9 \pm 0.5$ & np \\
\hline $17 / 18$ & $9.8 \pm 2.6$ & $5.4 \pm 1.5$ & $4.3 \pm 0.3$ & $3.3 \pm 0.4$ \\
\hline $21 / 22$ & $7.1 \pm 3.5$ & $5.2 \pm 2.7$ & $3.7 \pm 0.4$ & $3.0 \pm 0.9$ \\
\hline $25 / 26$ & $\mathrm{np}$ & $4.7 \pm 1.1$ & $3.8 \pm 0.3$ & $3.2 \pm 2.2$ \\
\hline $24 / 25$ & $7.8 \pm 3.9$ & $6.9 \pm 2.7$ & $4.3 \pm 1.4$ & $3.4 \pm 0.8$ \\
\hline
\end{tabular}

np, not present.

to a $\mathrm{LI}$ of $5.9 \%$. The in vitro BrdU-labelling data described in this paper are comparable with published data for in vivo injections, since a LI of $3.8-5.0 \%$ was reported for the basal cell layer of Yorkshire pigs using iv injections of ${ }^{3} \mathrm{H}$ thymidine [17]. In Large White pigs, a LI of $8.1 \%$ and $4.1 \%$ for basal and suprabasal layers, respectively, was found with an intradermal injection technique [18, 19].

Variations in epidermal thickness owing to undulations of the basal cell membrane ranged from an average of $63 \mu \mathrm{m}$ up to $117 \mu \mathrm{m}$. This is in the same range as for Large White pigs, where the epidermal thickness was estimated at 60-90 $\mu \mathrm{m}$ [20].

\section{Irradiated epidermis}

Clusters of BrdU-labelled cells could be counted in irradiated epidermis. For colonies containing $\geqslant 16$ BrdU-positive cells, the cell survival curves yielded $D_{0}$-values of around 3.5-4 Gy, irrespective of the time after irradiation that biopsies were taken. An $\mathrm{ED}_{50}$ value of 33.6 Gy for moist desquamation corresponded with $\approx 3$ colonies $\mathrm{cm}^{-2}$ at $14 / 15$ days after irradiation. In mouse epidermis, a comparison of gross skin responses with cell survival data gave similar results [8]. It was expected that the cell survival curves for the different time periods after irradiation would superimpose, as the colonies would only grow in size but not in number as time progressed. The data presented here clearly demonstrated that the number of colonies increased with time after irradiation (Figure 4). The slightly steeper cell survival curve at 25/26 days after irradiation is probably due to the limited number of dose points available. After a dose of $27 \mathrm{~Gy}$, only 327 colonies $\mathrm{cm}^{-2}$ were present in one skin field (Figure 4), while in another field the density of proliferating cells had the appearance of that of unirradiated epidermis, suggesting that all colonies had merged and that the epithelium was returning to normal. At 25/26 days after $27 \mathrm{~Gy}$, large numbers of colonies had merged, and for this reason the 27 Gy data were excluded from analysis. It is clear that this assay will produce unreliable results beyond 25/26 days for doses below $30 \mathrm{~Gy}$.

The $D_{0}$-values of $3.5-4 \mathrm{~Gy}$ for clonogenic cells in pig epidermis are much higher than that reported for mouse epidermis [6]. On average, a $D_{0}$ of $1.38 \mathrm{~Gy}$ was calculated, based on eight separate mouse studies. This difference in $D_{0}$-values could be explained by differences in depth dose distribution. Although different types of energy and sources were used in the mouse studies, the depth dose distribution was uniform over the epidermis and dermis. In this study, however, there was a rapid fall off in depth dose distribution for iridium-192, with the $100 \%$ isodose at the skin surface, while the $95 \%$ isodose was around the basal membrane and the $80 \%$ isodose covered the dermal fat layer [11]. Thus, epithelial clonogenic cells of the hair follicles received a lower dose compared with those in the basal membrane. Particularly after the higher doses, clonogenic cells from the hair follicles might have contributed substantially to re-epithelialization, resulting in more colonies than anticipated and hence higher $D_{0}$-values. This is also in agreement with cell density data in pig epidermis where a faster proliferation rate was noticed after higher doses [16], which would contribute to higher $D_{0}$-values. Although not quantified, a substantial number of colonies was always seen in the vicinity of hair follicles. These observations are in agreement with studies on hair follicular epithelium, which has not only an extensive clonogenic growth capacity $[21,22]$ but is also much more radioresistant in comparison with epithelium of the basal membrane [23]. This suggested that the epithelium of hair follicles played an important role in repopulation of the epidermis after higher doses of irradiation.

In another pig skin study, fields of $4 \mathrm{~cm} \times 4 \mathrm{~cm}$ were irradiated with $3 \mathrm{MeV}$ electrons, resulting in a uniform depth dose distribution [1]. At 19-21 days after irradiation, epidermal colonies were recognized by mitotic figures. The cell survival curve for colonies containing $\geqslant 32$ cells is added for comparison in Figure 5c. A $D_{0}$-value of $3.05 \pm 0.38 \mathrm{~Gy}$ was reported, which is similar to the $3.0 \pm 0.9$ Gy obtained in this study for 
colonies of $\geqslant 32$ BrdU-positive cells at 21/22 days after irradiation (Table 4). However, the number of colonies counted by Chen et al [1] is much lower, which could be attributed to a more uniform depth dose distribution and consequently a smaller contribution of follicular epithelium to re-epithelialization. However, it cannot be ruled out that some variables in their experimental setup, such as a different strain of pig (Landrace) and other anaesthetic procedures, could have contributed to this lower number of colonies [24].

The assumption that colonies arising from clonogenic cell survivors would only grow in size and not in number as time progressed needs to be reconsidered. This increase in colony number could be due to migration, increased levels of cytokines, or both. The observation that microcolonies and macrocolonies were often close together indicated that migration was an important factor in the re-epithelialization of the epidermis after irradiation. At 14/15 days after irradiation, clusters of different sized colonies could already be seen, independent of dose. Apparently shortly after colony formation, clonogenic cells detached, migrated some distance away from the original colony and started a new colony. This pattern of clonogenic cell migration is an effective mechanism for rapid repopulation of the epidermis after irradiation and was seen throughout the observation period. This might explain the fast colony number doubling time of $\approx 4$ days, which is in agreement with a reported doubling time of $\approx 3.3$ days in Yorkshire pig skin [25]. Rapid cell migration within colonies is strongly influenced by cytokines, which are essential for sustained growth of keratinocyte colonies, as indicated by in vitro data [26]. This rapid cell migration could easily result in detachment of clonogenic cells, which begin new colonies some distance away.

An alternative explanation for the observed differences in colony size is that not all clonogenic cell survivors began proliferation at the same time and/or that the growth rate of the colonies differed. Differences in colony size ranging from 4 cells up to $40-80$ cells per colony have been reported at 17-21 days after irradiation [25]. These differences in the onset of proliferation and the colony growth rate might have been enhanced by increased levels of cytokines, which play an important role in cell proliferation, differentiation and growth regulation [27]. Biopsying 30 irradiated skin fields per animal over a period of 10-26 days might have increased cytokine levels. Increased cytokine levels after tissue injuries such as wounding or burns, and the effects of cytokines on wound healing, are well documented [28-30]. These increased cytokine levels might in turn have recruited dormant clonogenic cell survivors and/or altered the growth rate of already existing colonies, resulting in colonies of different size. Evidence for increased cytokine levels came from the unirradiated skin biopsies in these animals. Once the first biopsies of the irradiated fields were taken, the number of BrdU-labelled cells in the unirradiated skin increased by a factor of 2.5-3 (Figure 2, pig $\mathrm{A}$ and $\mathrm{B}$ ). In contrast, BrdUpositive cells in unirradiated epidermis did not change very much throughout treatment when all irradiated skin fields were biopsied at the same time at 24/25 days after irradiation (Figure 2, pig $\mathrm{C}$ and D). This suggested a systemic effect of cytokines owing to frequent biopsying, i.e. wounding, over a period of 10-26 days. In this light, the significantly large number of $\mathrm{BrdU}$ labelled cells 4 days prior to irradiation in pig B $(p<0.008)$ could be explained with the knowledge that this animal had severe scratches and superficial skin wounds around the shoulders and neck on arrival. These wounds had healed completely at the time of irradiation and, as a consequence, the number of BrdU-positive cells in the unirradiated skin was at the control level but increased again after biopsying of the irradiated fields.

However, following irradiation there is no evidence for possible effects of cytokines on colony formation. If the observed increments in colony numbers over 14-26 days were due to increased cytokine levels, one would assume that biopsying all irradiated skin fields at the same time, i.e. no wounding over a prolonged period of time, would yield a cell survival curve similar to that for days $14 / 15$. The data obtained for $24 / 25$ days after irradiation gave a similar cell survival curve as those obtained for days 25/26, where frequent biopsying of the same animals (pigs A and B) occurred over a period of 10-26 days. Apparently, increased cytokine levels could influence proliferation in unirradiated epidermis, but had little or no effect on colony formation in irradiated epidermis. One has to assume that colony formation is already at a maximum rate, which cannot be influenced any further by cytokines.

Another explanation for the increments in colony numbers with time could be variability in the onset of colony formation in different pigs. Although variability between animals was observed, it did not reach levels of significance. For the three animals biopsied over a period of 10-26 days, $p$-values $>0.09$ were calculated, while similar values were obtained for the two animals biopsied at days 24/25: colonies with 4-8 cells $(p>0.42), \quad 9-15$ cells $(p>0.53), \quad 16-32$ cells $(p>0.19)$ and $\geqslant 32$ cells $(p>0.059)$.

The cell turnover time for proliferating cells in the colonies was estimated at $17-22 \mathrm{~h}$, independent of dose [16]. This would imply that small 
colonies containing 4-8 BrdU-positive cells at days 14/15 after irradiation could have generated colonies containing 16-32 proliferating cells at days $17 / 18$, provided all cells are proliferating. The number of colonies at the $\mathrm{ED}_{50}$ level for moist desquamation indicated that this is not the case (Table 3). At 14/15 days after irradiation, 146 small colonies (4-8 cells) were counted, while at days $17 / 18$ on average only 8.3 colonies (16-31 cells) were seen, indicating that the majority of these small colonies were abortive. On the other hand, excessive large numbers of small colonies were produced after higher doses, resulting in higher $D_{0}$-values (Table 4). Large numbers of small colonies, so-called microcolonies containing $<16$ cells, were also counted in whole epidermal sheets of rodent skin [3,31], mouse lip mucosa [32] and pig skin [16, 23]. These microcolonies gave higher $D_{0}$-values compared with the larger macrocolonies, in agreement with data obtained in this study. It was proposed that these small colonies represented transit cells with a limited proliferative capacity entering post-mitotic maturation. It was found that these microcolonies were more radioresistant $[33,34]$, which was also observed in this study as higher $D_{0}$-values. The limited proliferative capacity of these small colonies is clearly demonstrated by the fact that at 25/26 days after irradiation this category of colonies is totally absent (Figure 5d).

Another explanation for these large numbers of small colonies came from an extensive cell kinetic study in mouse tongue epithelium [35]. It was concluded that already sterilized clonogenic cells must have some proliferative capacity to compensate quickly for the excessive cell losses due to irradiation. However, the number of cell divisions turned out to be very limited for these sterilized clonogenic cells and they were therefore called abortive divisions. This resulted in large numbers of small colonies that did not progress to larger colonies. Data from this study confirmed the existence of large numbers of small, abortive colonies for up to 22 days after irradiation with hardly any growth in colony size (Figure 5). With time, only a very small proportion of these colonies progressed to larger colonies (Table 2), which emphasized the fact that the majority of these small colonies were abortive. Absence of these small colonies at $25 / 26$ days after irradiation also supported the conclusion by Dörr et al [35] that these colonies were abortive. Given these results, one has to consider that the small colonies of 4-8 BrdU-positive cells may have a different origin. The majority of these colonies came from transit cells and/or sterilized clonogenic cells and were scattered around in the basal layer, while a small proportion came from clonogenic cells detached from larger colonies. The latter category of small colonies can progress to larger colonies and will be seen mainly in the vicinity of the larger colonies.

This study demonstrated that the use of full thickness epidermal sheets is suitable for the investigation of colony formation after irradiation and that quantification of colony numbers can be used as an estimate for epidermal radiosensitivity. Small skin biopsies were used for enzymatic separation of epidermis and dermis followed by in vitro BrdU labelling, standard immunohistochemistry and preparation for light microscopy. This allowed a quantitative assessment of proliferating cells. Colonies containing $\geqslant 16$ BrdUpositive cells were first seen at $14 / 15$ days after single doses of 20-36 Gy. The number of colonies per $\mathrm{cm}^{2}$ decreased with increasing dose, which gave a $D_{0}$ of $3.9 \mathrm{~Gy}$. The $\mathrm{ED}_{50}$ value for the in vivo epidermal response of moist desquamation corresponded with 2.7 colonies $\mathrm{cm}^{-2}$. Surprisingly, the number of colonies increased with time after irradiation, which is contributed to by cell migration and/or substantial contributions of clonogenic cells from hair follicles owing to non-uniform depth dose distributions. BrdUpositive cells in unirradiated skin increased 2.5-3-fold once biopsying started, which suggested a systemic effect of increased cytokine levels. In contrast, these increased cytokine levels had no influence on colony formation. The majority of the microcolonies (4-8 cells) barely progressed to larger colonies. These microcolonies were more radioresistant compared with macrocolonies.

\section{Acknowledgments}

The authors thank Dr W Dörr for stimulating discussions and useful comments on the manuscript. Due acknowledgments are given to Miss M C Dekker and Mr R J H van Gurp (Laboratory for Experimental Patho-Oncology, Daniel den Hoed Cancer Center) for their technical advice and fruitful discussions on the immunohistochemistry. Financial support by the "NijbakkerMorra" foundation is greatly acknowledged. The authors thank $\mathrm{Mr} \mathrm{R}$ Spruyt of the "Erasmus Dierexperimenteel Centrum" for the day to day care of the animals.

\section{References}

1. Chen FD, Chen KY, Lee YL, Yu C. Effects of field size on the survival of pig epidermal colony-forming in situ after electron irradiation. Int $\mathbf{J}$ Radiat Biol 1995;67:79-83.

2. Van den Aardweg GJMJ, Mooi WJ. Determination of colony numbers in pig epidermis as an estimate for radiosensitivity. A rapid assay based on in vitro BrdU-labelling. Br J Radiol 1999;72:1104-9. 
3. Al-Barwari SE, Potten CS. Regeneration and doseresponse characteristics of irradiated mouse dorsal epidermal cells. Int J Radiat Biol 1976;30:201-16.

4. Chen FD, Hendry JH. The radiosensitivity of microcolony and macrocolony-forming cells in mouse tail epidermis. Br J Radiol 1986;59:389-95.

5. Hendry JH. Correlation of the dose-response relationships for epidermal colony-forming units, skin reactions, and healing, in the $\mathrm{X}$-irradiated mouse tail. Br J Radiol 1984;57:909-18.

6. Hendry JH. Survival of cells in mammalian tissues after low doses of irradiation: a short review. Int J Radiat Biol 1988;53:89-94.

7. Potten CS, Hendry JH, Al-Barwari SE. A cellular analysis of radiation injury in epidermis. In: Potten $\mathrm{CS}$, Hendry JH, editors. Cytotoxic insult to tissue. Effects on cell lineages. Edinburgh, UK: Churchill Livingstone, 1983:153-85.

8. Withers HR. The dose-survival relationship for irradiation of epithelial cells of mouse skin. $\mathrm{Br}$ J Radiol 1967;40:187-94.

9. Withers HR, Taylor JMG, Maciejewski B. Treatment volume and tissue tolerance. Int J Radiat Oncol Biol Phys 1988;14:751-9.

10. Archambeau JO, Bennett GW, Abata JJ, Brenneis HJ. Response of swine skin to acute single exposures of X-rays: quantification of the epidermal cell changes. Radiat Res 1979;79:298-337.

11. Hamm PCJ, Bakker EJ, van den Berg AP, van den Aardweg GJMJ, Visser AG, Levendag PC. Single dose irradiation response of pig skin: a comparison of brachytherapy using a single, high dose rate iridium-192 stepping source with $200 \mathrm{kV}$ X-rays. $\mathrm{Br}$ J Radiol 2000;73:762-70.

12. Van den Aardweg GJMJ, Hopewell JW. Manipulation of the radiosensitivity of pig epidermis by changing the concentration of oxygen and halothane in the anaesthetic gas mixture. Int J Radiat Biol 1989;56:1023-32.

13. Dickinson F, Hubbard N. The large white female pig in research related to cancer treatment: general husbandry and anaesthesia. Animal Technology 1190;41:35-41.

14. Kitano Y, Okada N. Separation of the epidermal sheet by dispase. Br J Dermatol 1983;108:555-60.

15. Normand J, Karasek MA. A method for the isolation and serial propagation of keratinocytes, endothelial cells, and fibroblasts from a single punch biopsy of human skin. In Vitro Cell Dev Biol Anim 1995;31:447-55.

16. Morris GM, Hopewell JW. Changes in the cell kinetics of pig epidermis after single doses of $\mathrm{X}$ rays. Br J Radiol 1988;61:205-11.

17. Archambeau JO, Bennett GW. Quantification of morphologic, cytologic and kinetic parameters of unirradiated swine skin: a histologic model. Radiat Res 1984;98:254-73.

18. Morris GM, Hopewell JW. Cell population kinetics in pig epidermis: further studies. Cell Tissue Kinet 1987;20:161-9.
19. Morris GM, Rezvani M, Hopewell JW, Franke H, Loeffler M. Epidermal cell kinetics in pig skin. Epithelia 1987;1:231-42.

20. Hopewell JW. Effects of radiation on the skin. Radiological Protection Bulletin 1985;62:16-24.

21. Rochat A, Kobayashi K, Barrandon Y. Location of stem cells of human hair follicles by clonal analysis. Cell 1994;76:1063-73.

22. Yang JS, Lavker RM, Sun TT. Upper human hair follicle contains a subpopulation of keratinocytes with superior in vitro proliferative potential. J Invest Dermatol 1993;101:652-9.

23. Morris GM, Hopewell JW. Cell kinetic changes in the folicular epithelium of pig skin after irradiation with single and fractionated doses of $\mathrm{X}$ rays. $\mathrm{Br}$ J Radiol 1989;62:41-7.

24. van den Aardweg GJMJ. Considerations about field-size effects after irradiation in pig epidermis as detected by a colony assay in situ. Int $\mathbf{J}$ Radiat Biol 1996;69:405-6.

25. Archambeau JO, Gerber A, Ayoub R, Brenneis HJ. Epidermal-cell population changes produced by exposure to $2300 \mathrm{R}$. Radiology 1972;103:191-6.

26. Barrandon Y, Green H. Cell migration is essential for sustained growth of keratinocytes colonies: the roles of transforming growth factor- $\alpha$ and epidermal growth factor. Cell 1987;50:1131-7.

27. Cross M, Dexter TM. Growth factors in development, transformation, and tumorigenesis. Cell 1991; 64:271-80.

28. Ansel JC, Tiesman JP, Olerud JE, Krueger JG, Krane JF, Tara DC, et al. Human keratinocytes are a major source of cutaneous platelet-derived growth factor. J Clin Invest 1993;92:671-8.

29. Brown GL, Nanney LB, Griffen J, Cramer AB, Yancey JM, Curtsinger LJ, et al. Enhancement of wound healing by topical treatment with epidermal growth factor. New Engl J Med 1989;321:76-9.

30. Gailit J, Clark AF. Wound repair in the context of extracellular matrix. Curr Opin Cell Biol 1994;6: 717-25.

31. Denekamp J, Stewart FA, Douglas BG. Changes in the proliferation rate of mouse epidermis after irradiation: continuous labelling studies. Cell Tissue Kinet 1976;9:19-29.

32. Morris GM, Landuyt W, Whitehouse E, Vanuytsel L, Hopewell JW. Radiation response of mouse lip mucosal epithelium: a cell kinetic study. Int J Radiat Biol 1993;63:509-17.

33. Morris GM. Review article: effects of radiation on the cell proliferaton kinetics of epithelial tissuestherapeutic implications. $\mathrm{Br}$ J Radiol 1996;69: 795-803.

34. Potten CS. The cell kinetic mechanism for radiation-induced cellular depletion of epithelial tissue based on hierarchical differences in radiosensitivity. Int J Radiat Biol 1981:40:217-25.

35. Dörr W, Emmendorfer H, Haide E, Kummermehr J. Proliferation equivalent of 'accelerated repopulation' in mouse oral mucosa. Int J Radiat Biol 1994; 66:157-67. 